\title{
Cooling performance of Ceiling Radiant Textile Air Conditioning System with Ceiling Cassette Unit of Packaged Air Conditioner
}

\author{
Toshio Yamanaka ${ }^{1, *}$, Mari Kuranaga ${ }^{1}$, Tatsunori Maeda ${ }^{2}$, and Haruto Kitakaze ${ }^{1}$ \\ ${ }^{1}$ Osaka University, Graduate School of Engineering, 2-1 Yamadaoka Suita Osaka, Japan \\ ${ }^{2}$ Takenaka Corporation, 4-1-13 Hommachi Chuo-ku Osaka, Japan
}

\begin{abstract}
The authors developed a new radiant air conditioning system named ceiling radiant textile air conditioning system with ceiling cassette unit of packaged air conditioner (PAC). The nonflammable textile is stretched under the ceiling with ceiling cassette units of PAC with a distance of around $30 \mathrm{~cm}$. The aim of this study is to investigate the cooling performance of this new radiant system, so the experiments with full scale model were conducted for three system. The first system is "textile only", the second system is "textile with guide for air return grille" and the third system is "textile with guide and opening for air return grille". Airflow rate through textile is measured by tracer gas method. In all cases, the vertical temperature distribution is almost uniform, and the cooling effect of "textile with guide and opening for air return grille" is the largest. As for the radiant effect, two systems of "only textile" and "textile with guide for air return grille" are superior to "textile with guide and opening for air return grille". The airflow rate trough textile is doubled when using guide, and increased by five times if the opening was provided under the guide.
\end{abstract}

\section{Introduction}

As a radiant air conditioning system[1], water supply type system is usually used [2], but sometimes it is avoided due to the risk of water leakage in the case of earthquake in the countries with frequent earthquakes like Japan. So various air supply types of radiant air conditioning system are gradually developed [3][4], and being used in commercial buildings.

So the authors are developing a new radiant air conditioning system based on air using PAC (Packaged Air Conditioner) on the ceiling. In Fig.1, the section of the room with textile below the ceiling with some PACs is shown. It is known that this kind of PAC often cause draft of occupants due to high velocity of supply jets from the units, but this new radiant air conditioning system can eliminate the risk of discomfort caused by the draft. The textile must be nonflammable and air-permeable. Due to the instability caused by cold and dense air above the textile, the cold air in the space above the textile flows down to the indoor space through the textile. This airflow induces the reverse airflow entering the upper space above the textile. In this study this upper space is called virtual "attic" conveniently. The space below the textile ("indoor space") will be cooled down due to exchange airflow. Additionally, the cold radiation from the cold textile to the occupants can be expected, that is described as "radiant effect" in Fig.1. In order to design this system, the key variable is the exchange airflow rate and textile temperature, but is not so easy to predict the exchange airflow rate. The problem is whether enough mount of airflow rate can be obtained or not, so the other device might be needed to increase the exchange airflow rate.

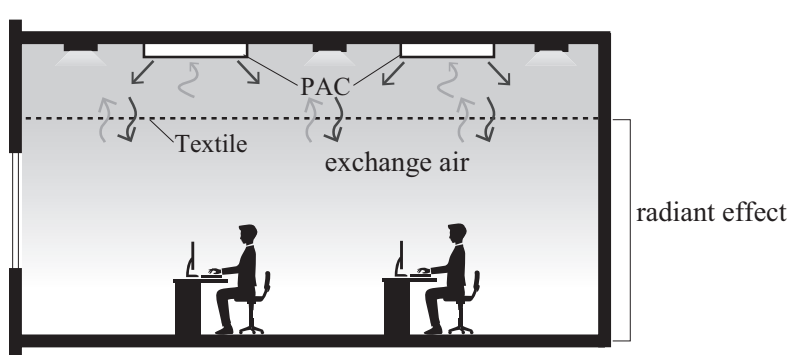

Fig. 1. Ceiling Radiant Textile Air Conditioning System. In this paper, in order to examine the possibility of this kind of Ceiling Radiant Textile Air Conditioning (CRTAC) the results of cooling experiment using fullscale experimental chamber is presented. Here, 4-way cassette type PAC was used and three textile systems (with/without guide for air return to PAC and also with the guide with opening) are tested. The measurement of temperature, the concentration of $\mathrm{CO} 2$ as a tracer gas and the radiative heat flow were measured.

\section{Experimental setup}

\subsection{Full scale experimental room}

For the experiment, the full-scale experimental chamber in Fig. 2 was used. This chamber was installed in the laboratory made of RC (reinforced concrete), and the wall of chamber was made of glass wool $(50 \mathrm{~mm})$ and plaster

"Corresponding author: yamanaka@arch.eng.osaka-u.ac.jp 
board $(12.5 \mathrm{~mm})$. The inside size of the chamber is $4.41 \mathrm{~m}(\mathrm{D}) \times 4.01 \mathrm{~m}(\mathrm{~W}) \times 3.44 \mathrm{~m}(\mathrm{H})$, and the ceiling height (from floor to textile) is $3.14 \mathrm{~m}$. The textile is stretched under the ceiling with a distance of $0.3 \mathrm{~m}$. The characteristics of used textile are listed in Table 1. The air permeability is rather small. Two 4-way type PACs (Mitsubishi Electric Corporation, PLZ-ERP140EF) are installed on the ceiling. This PAC controls the supply air temperature based on the measured temperature by the thermal censor located inside the return air grille of PAC. Inside the chamber, various heat sources are installed such as four black bulbs $(53 \mathrm{~W} \times 4)$ simulating occupants at $60 \mathrm{~cm}$ height above the floor, four black metal boxes including a bulb $(100 \mathrm{~W})$ simulating heat from different apparatus and four electric floor heaters $(50 \mathrm{~W} x 4)$ on the floor simulating lighting etc.. The total heat generation is basically $812 \mathrm{~W}$, but in some cases (see Table 2), $412 \mathrm{~W}$ (without four bulbs inside metal box) and 1,236W with eight additional black bulbs were emitted.

Table 1. Characteristics of textile for experiment.

\begin{tabular}{|l|l|}
\hline Materials & $\begin{array}{l}\text { glass fiber woven } \\
\text { fabric sticked on } \\
\text { polyester fiber } \\
\text { nonwoven fabric }\end{array}$ \\
\hline Discharge coefficient [-] & 0.013 \\
\hline Pressure loss coefficient [-] & 5697 \\
\hline
\end{tabular}

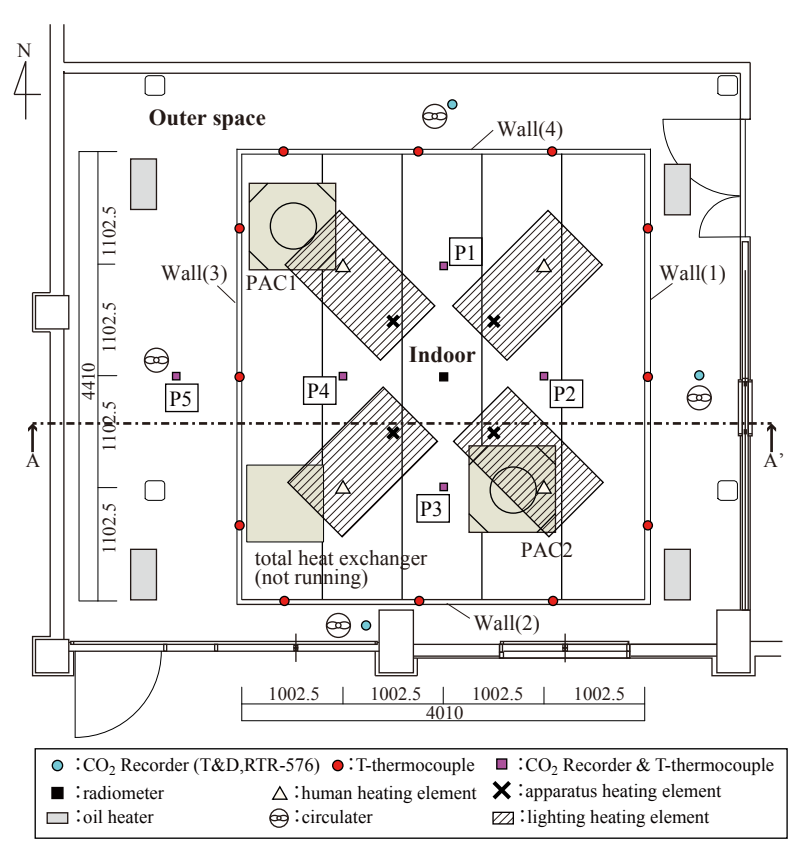

Fig. 2. Plan of experimental room.

In outer space around the chamber, four oil heaters (radiator filled with oil with electric heater inside) and four circulation fans are installed to control the air temperature in the outer and make the concentration distribution of tracer gas (CO2) uniform by mixing.

The measurement points of temperature and $\mathrm{CO} 2$ concentration are listed in Fig. 2 and Fig. 3. Thermocouples ( $\mathrm{T}$ type) and portable $\mathrm{CO} 2$ recorder (analyzer) (T\&D, RTR-576 : 0-9999ppm, $\pm 50 \mathrm{ppm} \pm 5 \%$ of Reading) were used for measurement. The measured data was corrected by the calibration data obtained by the air of several $\mathrm{C} 02$ concentrations. The radiative heat flow into the radiometer (EKO Instruments Co., Ltd., MR-60) was measured at the center of the chamber with the height of $1.1 \mathrm{~m}$ above the floor.

The experiment started afternoon and after the steady state of heat flows were confirmed by the temperature variations at many points, $\mathrm{CO} 2$ gas was generated with a constant injection rate of $1 \mathrm{~L} / \mathrm{min}$ at the air return grille, and the $\mathrm{CO} 2$ concentrations were measured for three hours.

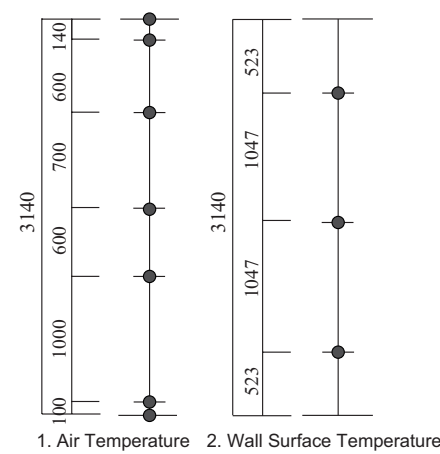

(a) T-thermocouple

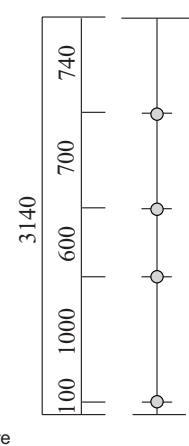

(b) $\mathrm{CO}_{2}$ recorder
Fig. 3. Measurement point of temperature and $\mathrm{CO}_{2}$ concentration (vertical layout).

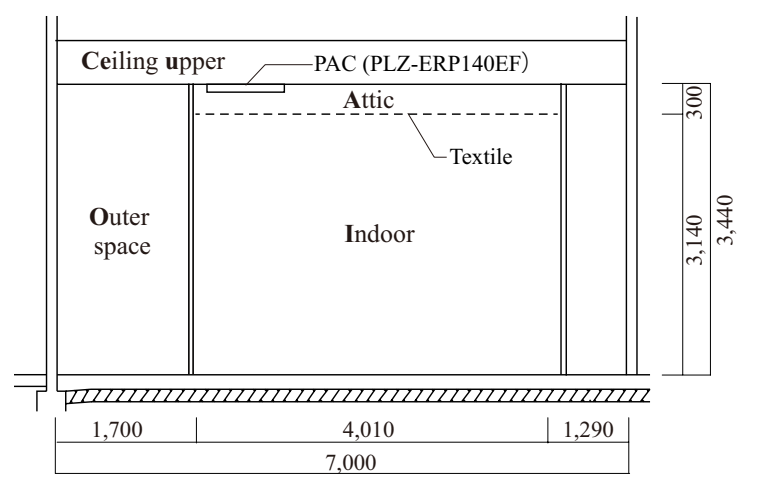

Fig. 4. Section of experimental room (A-A' section in Fig.2).

\subsection{Experimental conditions and parameters}

In the experiments, three types of textile system were introduced as is shown in Fig.5.

(a) textile only

(b) textile with guide for air return grille

(c) textile with guide and opening for air return grille Installation of the guide was intended to make a pressure difference across the textile for keep the enough mount of exchange airflow. Opening of (c) is used to get rid of the flow resistance of textile.

For each textile system of Fig.5, six cases of condition were set as Table 2. Case 1 is the standard condition and in the other five cases only one or two conditions were changed from Case1. The changed values from the standard condition is written in bold types. In total, 18 cases of experiments were conducted. 


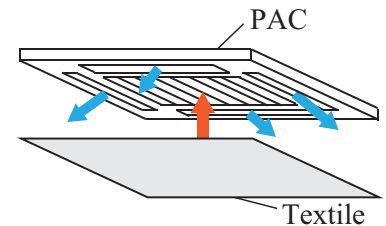

(a) textile only

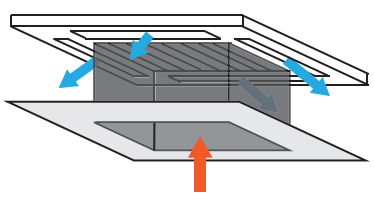

(c) textile with guide and opening for air return grille

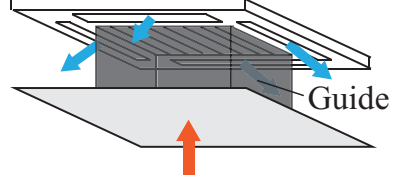

(b) textile with guide for air return grille

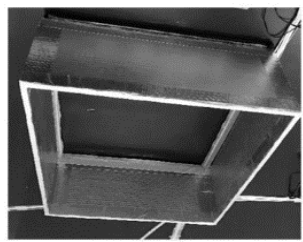

Fig. 5. Three systems of textile with/without guide.

Table 2. Experimental conditions.

\begin{tabular}{|c|c|}
\hline \multicolumn{2}{|c|}{ Case 1 (Normal) } \\
\hline \multicolumn{2}{|c|}{ Pre-set return air temperature* : $19\left[{ }^{\circ} \mathrm{C}\right]$} \\
\hline Airflow rate of PAC : & $1,016 \times 2\left[\mathrm{~m}^{3} / \mathrm{h}\right]$ \\
\hline Angle of supply air** : & 60 [degree] \\
\hline Total heat generation rate : & $812[\mathrm{~W}]\left(46\left[\mathrm{~W} / \mathrm{m}^{2}\right]\right)$ \\
\hline Oil heater pre-set temperature : & (a)- (b) $14(\mathrm{c}) 18\left[{ }^{\circ} \mathrm{C}\right]$ \\
\hline \multicolumn{2}{|c|}{ Case 2 (Low heat load) } \\
\hline \multicolumn{2}{|c|}{ Pre-set return air temperature* : $19\left[{ }^{\circ} \mathrm{C}\right]$} \\
\hline Airflow rate of PAC : & $1,016 \times 2\left[\mathrm{~m}^{3} / \mathrm{h}\right]$ \\
\hline Angle of supply air** : & 60 [degree] \\
\hline Total heat generation rate : & $412[\mathbf{W}]\left(23\left[\mathrm{~W} / \mathrm{m}^{2}\right]\right)$ \\
\hline Oil heater pre-set temperature : & $\overrightarrow{\text { (a) }-(\mathrm{b}) 14}$ (c) $18\left[{ }^{\circ} \mathrm{C}\right]$ \\
\hline \multicolumn{2}{|l|}{ Case 3 (Small airflow rate of PAC) } \\
\hline \multicolumn{2}{|c|}{ Pre-set return air temperature* : $19\left[{ }^{\circ} \mathrm{C}\right]$} \\
\hline Airflow rate of PAC : & $717 \times 2\left[\mathrm{~m}^{3} / \mathrm{h}\right]$ \\
\hline Angle of supply air** : & $\overline{60 \text { [degree] }}$ \\
\hline Total heat generation rate : & $812[\mathrm{~W}]\left(46\left[\mathrm{~W} / \mathrm{m}^{2}\right]\right)$ \\
\hline Oil heater pre-set temperature : & (a)- (b) $14(\mathrm{c}) 18\left[{ }^{\circ} \mathrm{C}\right]$ \\
\hline \multicolumn{2}{|c|}{ Case 4 (High temperature setting) } \\
\hline \multicolumn{2}{|c|}{ 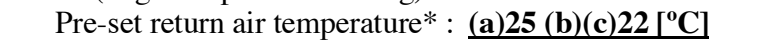 } \\
\hline Airflow rate of PAC : & $1,016 \times 2\left[\mathrm{~m}^{3} / \mathrm{h}\right]$ \\
\hline Angle of supply air** : & 60 [degree] \\
\hline Total heat generation rate : & $812[\mathrm{~W}]\left(46\left[\mathrm{~W} / \mathrm{m}^{2}\right]\right)$ \\
\hline Oil heater pre-set temperature : & (a)- (b) (c) $18\left[{ }^{\circ} \mathrm{C}\right]$ \\
\hline \multicolumn{2}{|c|}{ Case 5 (30 degree supply air from the horizontal) } \\
\hline \multicolumn{2}{|c|}{ Pre-set return air temperature* : $19\left[{ }^{\circ} \mathrm{C}\right]$} \\
\hline Airflow rate of PAC : & $1,016 \times 2\left[\mathrm{~m}^{3} / \mathrm{h}\right]$ \\
\hline Angle of supply air**: & 30 [degree] \\
\hline Total heat generation rate : & $812[\mathrm{~W}]\left(46\left[\mathrm{~W} / \mathrm{m}^{2}\right]\right)$ \\
\hline Oil heater pre-set temperature : & (a)- (b) $14(\mathrm{c}) 18\left[{ }^{\circ} \mathrm{C}\right]$ \\
\hline \multicolumn{2}{|l|}{ Case 6 (High heat load) } \\
\hline \multicolumn{2}{|c|}{ Pre-set return air temperature* : $19\left[{ }^{\circ} \mathrm{C}\right]$} \\
\hline Airflow rate of PAC : & $1,016 \times 2\left[\mathrm{~m}^{3} / \mathrm{h}\right]$ \\
\hline Angle of supply air** : & 60 [degree] \\
\hline Total heat generation rate : & 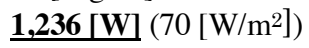 \\
\hline Oil heater pre-set temperature : & (a)- (b) $14(\mathrm{c}) 18\left[{ }^{\circ} \mathrm{C}\right]$ \\
\hline
\end{tabular}

Note:(a) textile only

(b) textile with guide for air return grille

(c) textile with guide and opening for air return grille (see Fig.5.)

* pre-set air temperature is applied to the return air of PAC that is almost equal to the air temperature in the attic, not the room temperature

** angle of supply air from the vertical line
In the experiments of (b) and (c), due to cold outdoor climate, it was impossible to cooling operation of PAC without oil heater in outer space of chamber, so the oil heaters were used to heat up the outer space and reduce the heat loss through walls of the chamber.

\section{Result of experiment and discussions}

\subsection{Temperature}

Temperature fluctuations at representative points under the case 1 and (a)textile only are shown in Fig.6. Though the indoor temperature is rather stable at around $23-24{ }^{\circ} \mathrm{C}$, the temperatures of indoor air, return air to PAC and supply air from PAC are fluctuation with a range of $10{ }^{\circ} \mathrm{C}$ with a period. It is supposed that the exchange airflow rate through textile is not enough large to cool down the indoor temperature in comparison to small attic volume above the textile.

In Fig.7, the change of temperature at each point in a fluctuation cycle (Case1) of three textile system (a)-(c). From these figures, the difference between indoor temperature and the temperatures of attic, supply, return etc. in the case of (b)guide or (c)guide and opening are smaller than the case of (a)textile only, and result of the (c) shows the smallest temperature difference across the textile. It can be supposed that the airflow rate through textile could be the largest owing to the guide and opening. The vertical distributions of air and textile temperature are shown in Fig.7. The results of six cases are drawn in each graph of three textile system of (a)-(c). The temperature of the textile surface (lower side) is shown on the broken line. These temperatures are averaged data during a cyclic period. In any cases, the vertical air temperature distribution is quite uniform and it can be said that the guideline of ASHRAE 55 [5] of $3{ }^{\circ} \mathrm{C}$ difference of vertical temperature difference in occupied zone. As for the indoor temperature (below textile), textile system of (c)guide and opening is the lowest and shows the best cooling effect among three. In the case of (a)textile only, the difference among the six cases are largest.

It can be said that the guide under the PAC and an opening for air return grille are effective to cool the indoor space.

\subsection{Surface temperature of textile}

The radiative heat flow into the horizontal plate at the height of $1.1 \mathrm{~m}$ above the floor was measured by radiometer, and the surface temperatures of the textile, wall and floor were calculated by the following equations. (Nomenclatures is at the end of this paper.) Here, the emissivity of the textile was assumed to be 0.99 .

$$
\begin{aligned}
& \Delta R_{m}=\Delta R-\varepsilon \sigma \sum_{n=1}^{4} \varphi_{n}\left(T_{W_{n}}{ }^{4}-T_{d}{ }^{4}\right) \\
& T_{m}=\sqrt[4]{\Delta R_{m} / \varepsilon \sigma \varphi_{m}+T_{d}{ }^{4}}
\end{aligned}
$$




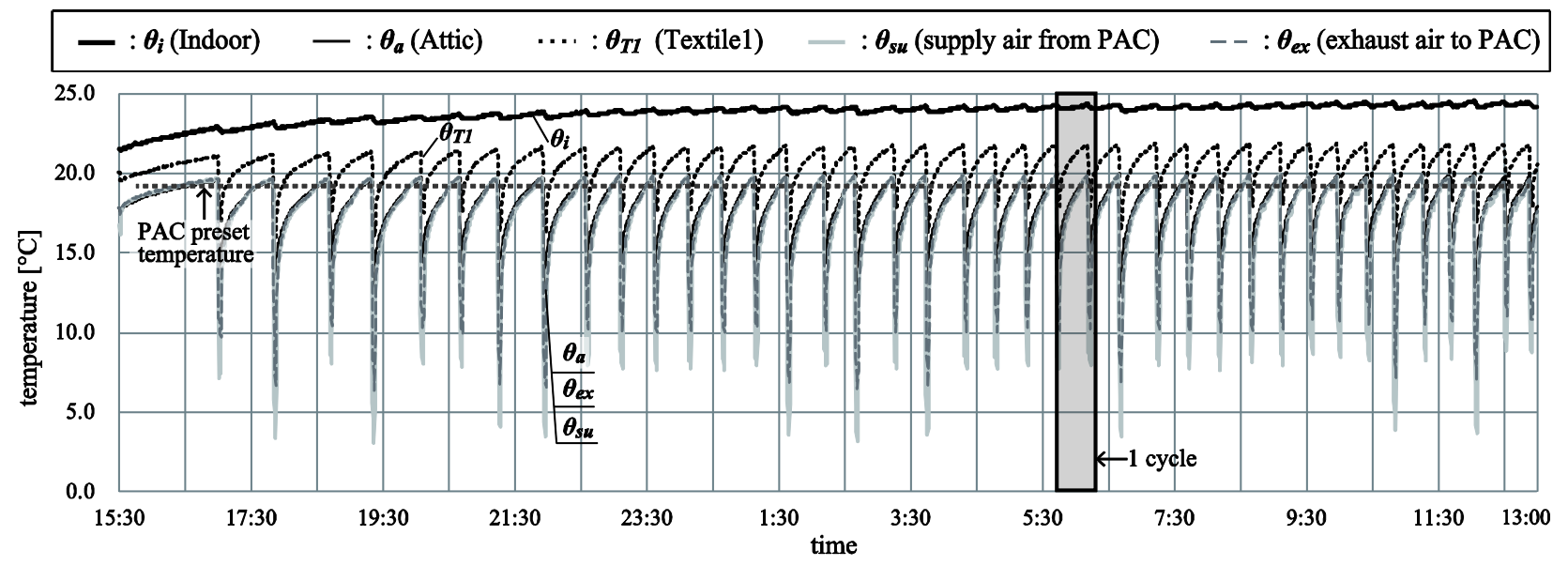

Fig. 6. Change of temperature at each points in total experiment time ((a) textile only, Case1).

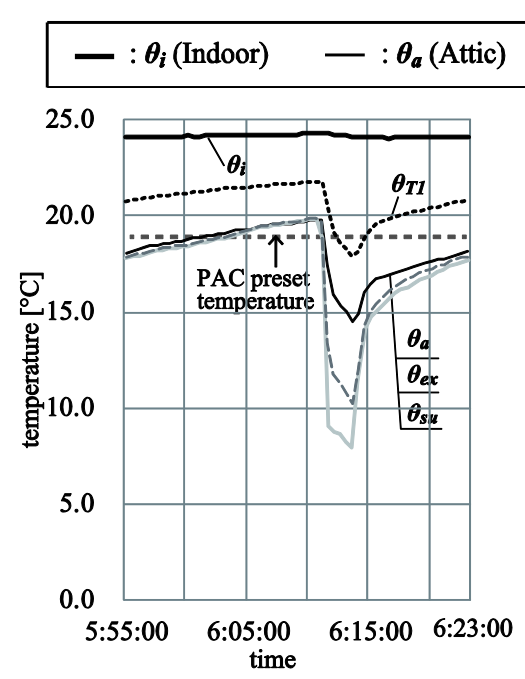

(a) textile only

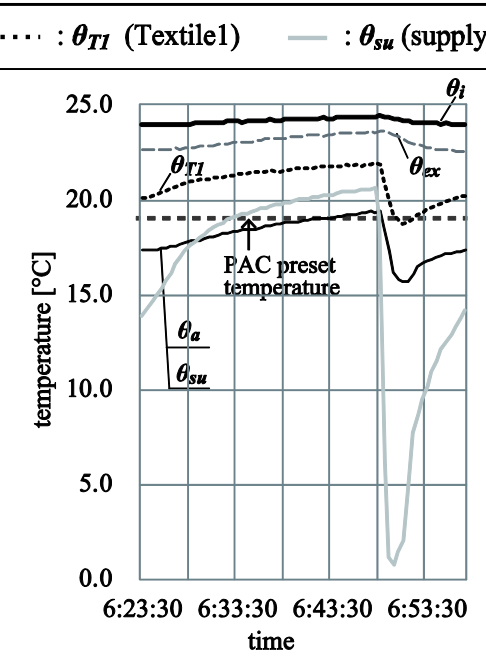

(b) guide

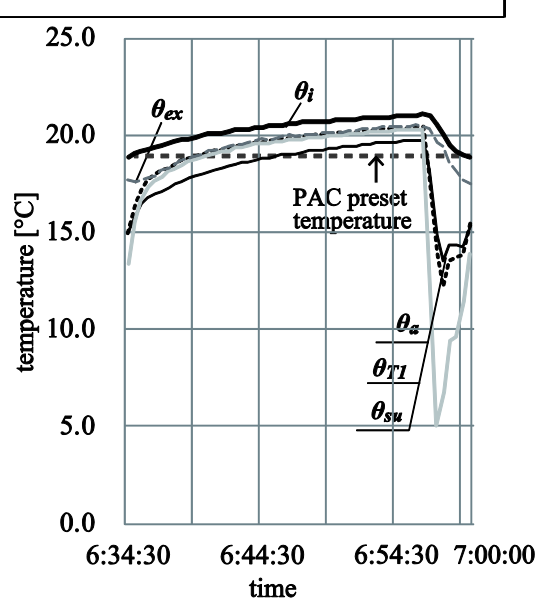

(c) guide and opening

Fig. 7. Change of temperature at each point in a fluctuation cycle (Case1).

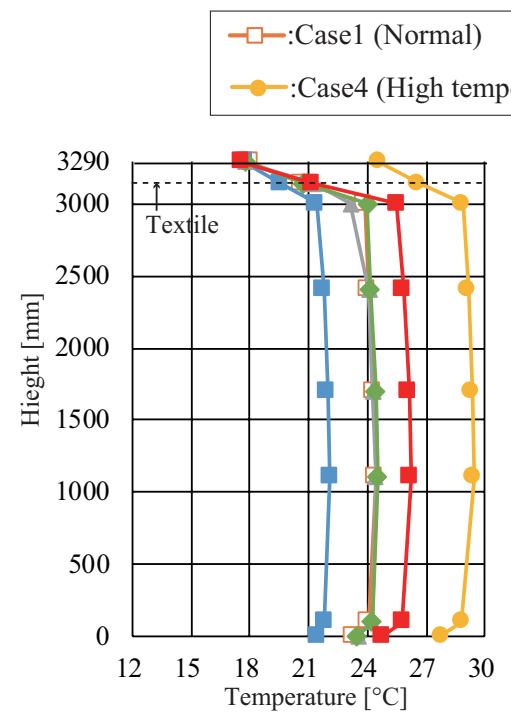

(a) textile only

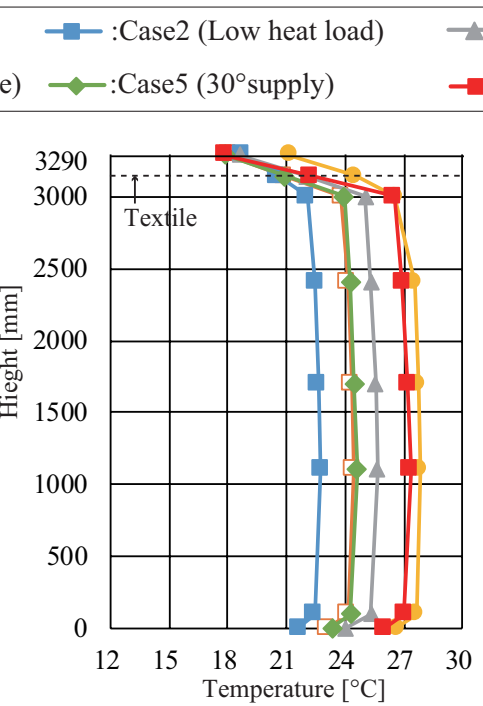

(b) guide
- $:$ Case3 (Small flow rate of PAC)

$\rightarrow-$ :Case6 (High heat load)

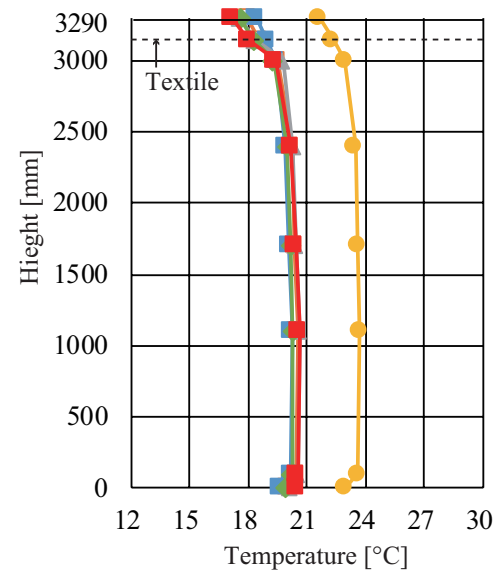

(c) guide and opening

Fig. 8. Vertical temperature distribution of each textile system. 


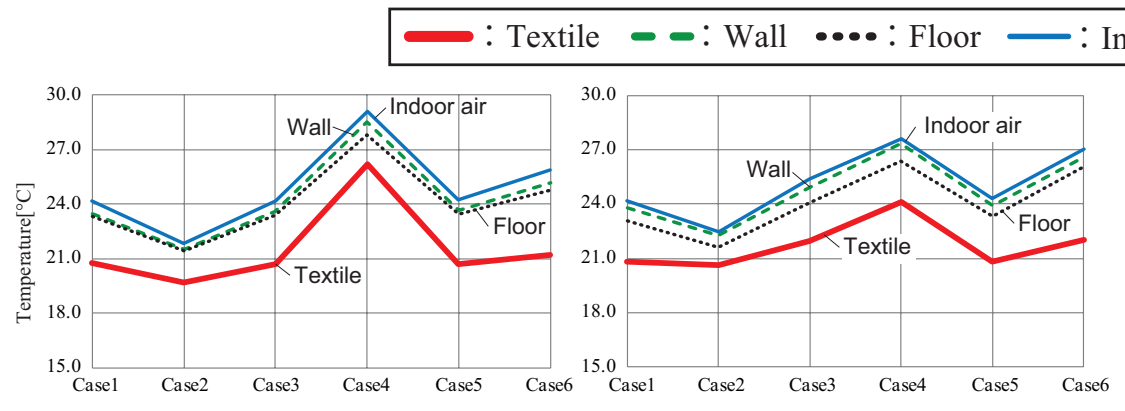

(a) textile only (b) guide

\section{oor Air}

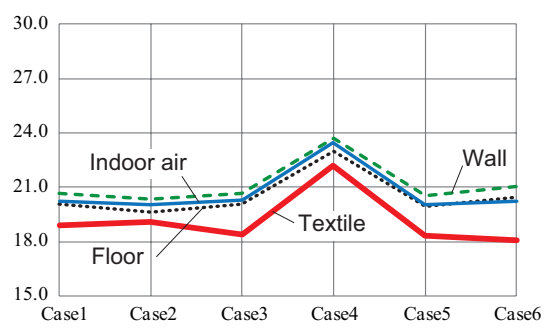

(c) guide and opening

Fig. 9. Surface temperature and air temperature.

The Fig. 9 shows the temperatures of the surface of textile, wall surface, floor surface and indoor air. The temperatures in the case 4 show the highest temperature as the pre-set temperature is high in this case, and in the case 6 also high because of the high heat generation rate inside the room. From Fig.8, the highest cooling effect of (c)guide and opening could be confirmed.

\subsection{Exchange airflow rate through texitle}

From the measured data of $\mathrm{CO} 2$ concentration in each space, that is, indoor space below the textile, attic space above the textile and outer space around the chamber exchange airflow rates were calculated by the following equations of (3)-(6). In Fig.10, the definition of each airflow is shown schematically.

$$
\begin{aligned}
C_{a}^{n+1}= & C_{a}^{n}+\left(C_{i}^{n} Q_{2}+M-C_{a}^{n} Q_{1}+C_{o}^{n} Q_{5}-C_{a}^{n} Q_{6}\right) \frac{\Delta t}{V_{a}} \\
C_{i}^{n+1}= & C_{i}^{n}+\left(C_{a}^{n} Q_{1}+C_{o}^{n} Q_{4}-C_{i}^{n} Q_{3}-C_{i}^{n} Q_{2}\right) \frac{\Delta t}{V_{i}} \\
& -Q_{1}+Q_{2}+Q_{5}-Q_{6}=0 \\
& Q_{1}-Q_{2}-Q_{3}+Q_{4}=0
\end{aligned}
$$

For the calculation of airflows, the least square method was used. The obtained airflow rate of Q1 and Q2 are listed in Table 3 with the temperature difference across textile. Comparing them with the airflow rate of (a) textile only, the airflow rate increases by 1.2-2.0 times because of the installation of guide, and 5.5-7.0 times because of the installation of both guide and openings. This shows the flow resistance, that is, pressure loss coefficient of this textile is quite large.

The ratios of airflow rate are compared between cases in Fig.11. In the case of (a) textile only, case 3 with the low

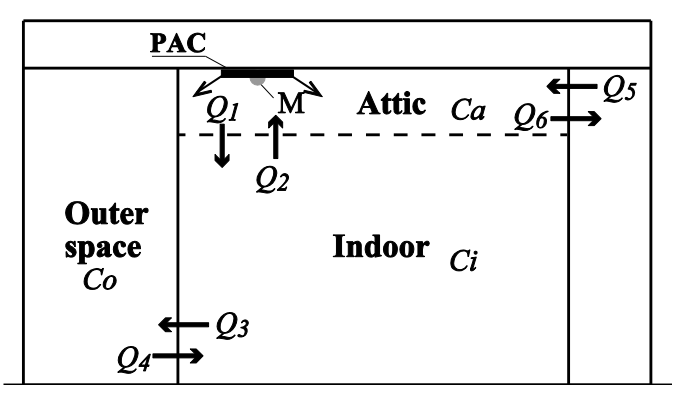

Fig. 10. Schematic diagram of exchange airflow rate. supply airflow rate from PAC shows low rate of airflow, and also case 2 with low heat load shows low airflow rate. In the cases of (b) and (c), case 3 with only the low supply airflow rate shows the smallest airflow rate. This is caused by forced airflow by the mechanical fan of PAC. These air flow rate can be calculated if the fan characteristics and the pressure loss coefficient are known previously. Nevertheless, it is difficult to predict the airflow rate in the case of (a) textile only because this phenomenon is due to instability of buoyancy across horizontal textile. So, in order to develop the empirical method to predict the exchange airflow rate through textile, the correlation between some parameters. In Fig.12, the relationship between temperature difference across the textile and airflow rate ((a)textile only) is shown. As for both of Q1 and Q2, the good correlation can be seen with high value of coefficient of determination, which are 0.82 and 0.78 . If airflow rate is divided by textile area, the air velocity can be obtained, which can be applied to another room configuration. The inconsistency of Q1 and Q2 seems to be induced by the infiltration through the walls, so more precise data should be needed in the future research.

Table 3. Temperature difference across textile $\Delta \theta\left[{ }^{\circ} \mathrm{C}\right]$ and airflow rate through textile $\left[\mathrm{m}^{3} / \mathrm{h}\right]$

\begin{tabular}{c|c|c|c|c|c|c|c|c|c}
\hline & \multicolumn{3}{|c|}{ (a)no guide } & \multicolumn{3}{c|}{ (b) guide on textile } & \multicolumn{3}{c}{ (c) guide with opening } \\
\cline { 2 - 11 } & $\boldsymbol{\Delta} \boldsymbol{\theta}$ & $\boldsymbol{Q}_{\mathbf{1}}$ & $\boldsymbol{Q}_{\mathbf{2}}$ & $\Delta \boldsymbol{\theta}$ & $\boldsymbol{Q}_{\mathbf{1}}$ & $\boldsymbol{Q}_{\mathbf{2}}$ & $\Delta \boldsymbol{\theta}$ & $\boldsymbol{Q}_{\mathbf{1}}$ & $\boldsymbol{Q}_{\mathbf{2}}$ \\
\hline Case1 & 6.3 & 90.3 & 116.0 & 6.0 & 156.1 & 182.9 & 2.4 & 986.9 & 1016.1 \\
\hline Case2 & 3.8 & 79.9 & 94.7 & 4.0 & 154.8 & 182.3 & 1.5 & 990.6 & 1019.0 \\
\hline Case3 & 5.0 & 78.6 & 101.0 & 6.9 & 111.4 & 132.8 & 2.9 & 811.5 & 850.4 \\
\hline Case4 & 4.7 & 92.2 & 106.3 & 6.3 & 147.8 & 178.5 & 1.9 & 958.0 & 1008.8 \\
\hline Case5 & 6.5 & 85.9 & 106.4 & 6.3 & 144.2 & 175.8 & 2.3 & 975.3 & 1043.5 \\
\hline Case6 & 8.2 & 91.8 & 120.1 & 9.2 & 155.7 & 187.6 & 3.0 & 972.0 & 1018.7 \\
\hline
\end{tabular}



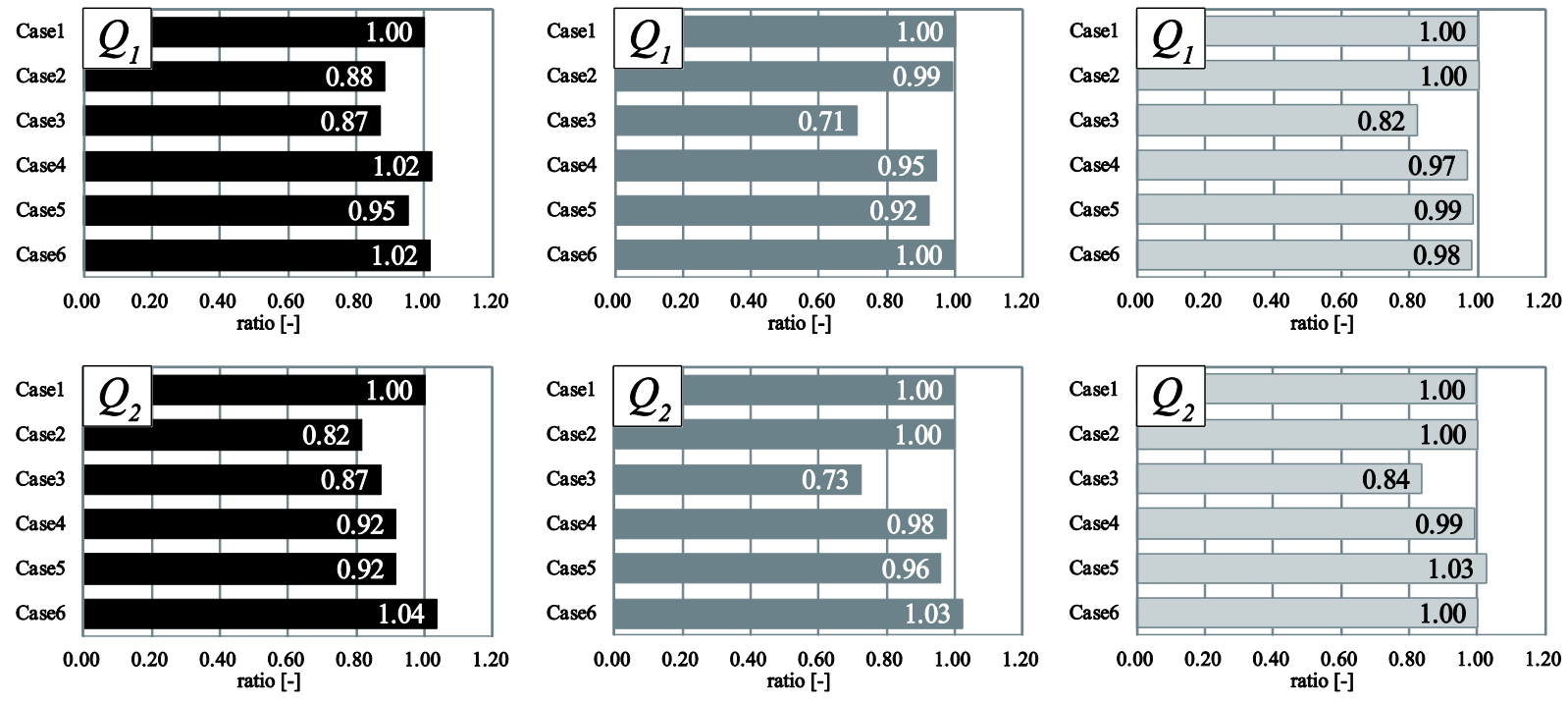

(a) textile only

(b) guide

(c) guide and opening

Fig. 11. Ratio of airflow rate $Q_{1}$ and $Q_{2}$ to each airflow rate of Case1

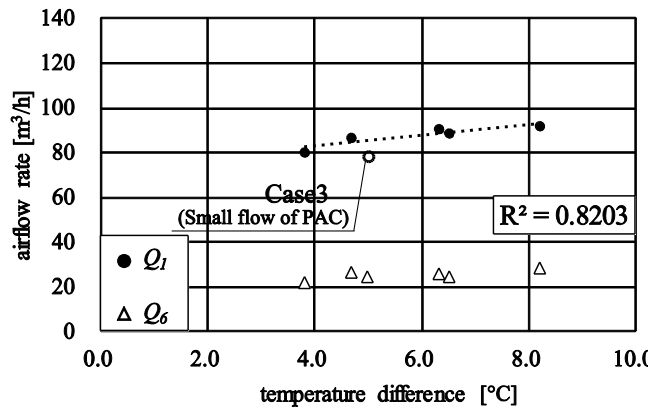

(1) Outflow from Attic

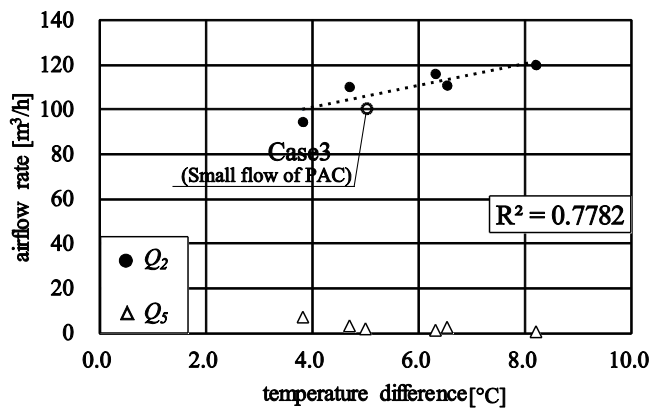

(2) Inflow to Attic

Fig. 12. Relationship between temperature difference across textile and airflow rate ((a)textile only).

\subsection{Removed heat from room by PAC}

To confirm the cooling effect of PAC in each condition, the removed heat rate from the room by PAC was calculated by the following equation.

$$
q_{P A C}=c_{p} \rho \cdot\left(\theta_{e x}-\theta_{s u}\right) Q_{P A C}
$$

The heat rate removed from the room was shown in Fig.12. It shows good cooling capacity of the system of (c) guide and opening. The textile with guide and opening, however, has an esthetic problem, because the flat textile will be more beautiful than the textile with large openings. So the more permeable textile to permit the larger airflow rate though textile should be applied.

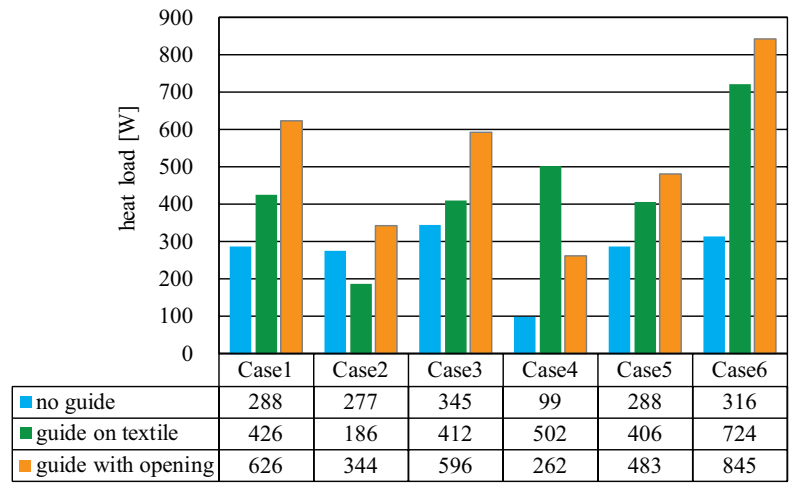

Fig. 13. Sensible heat rate removed from attic by PAC.

\section{Conclusion}

The cooling effect of the Ceiling Radiant Textile Air Conditioning (CRTAC) in various conditions were examined by the experiment with full scale room chamber.

As a result, the following remarks were obtained.

- Among three systems of textile, (a)textile only, (b)guide, (c) guide and opening, the cooling effect is turned out to be $(\mathrm{c})>(\mathrm{b})>(\mathrm{a})$, because of the amount of airflow rate through the textile.

- Among six cases with different values of various parameter, the effect of heat load inside the chamber is the largest in all textile systems, and also supply air flow rate of PAC is large in the system with the guide of (b) and (c). 
- The vertical distribution of air temperature is quite uniform in any cases of three systems, which means no discomfort will be felt by occupant due to vertical air temperature difference.

- The airflow rate of each can be identified by means of tracer gas technique using $\mathrm{CO} 2$ gas. The ratio of the airflow rate to the textile system (a)textile only is 1.22.0 in the case of (b), and 5.5-7.0 in the case of (c).

- From the calculation of removed heat by PAC, the cooling effect of (c)guide and opening is the largest and that of (b) guide is the second largest.

- The airflow through the textile has high correlation with the air temperature difference across the textile under the system of (a)textile only, so the airflow rate can be predicted from the air temperature difference across the textile.

- More permeable textile is worth testing in the following research.

The authors are grateful to Takenaka Corporation which funded this research, and appreciate heartily the discussion with the late Prof. Kotani Hisashi who passed away in December 2017.

\section{References}

1. 2012 ASHRAE Handbook - HVAC Systems and Equipment(SI) Chapter6 Panel heating and cooling

2. Kyu-Nam Rhee and Kwang Woo Kim (Kyu-Nam Rhee, 2015) A 50 year review of basic and applied research in radiant heating and cooling systems for the built environment. Building and Environment 91, pp.166-190, 2015

3. Kohata, Y. Hayama, H. and Sekiguchi, K.: Study on All Air Radiation Air-Conditioning System of Task Ambient, Journal of Environmental Engineering (Transaction of AIJ), Vol,80, No.710, pp.351-358, 2015.4 (in Japanese)

4. Tara, T. Yamanaka, T. Mizuide, K.and et: Indoor Environment of Convective \& Radiative AirConditioning System in Office Building Supplied from Whole Ceiling by Punched Metal (Part2-4), Technical papers of annual meetings, the Society of Heating, Air-conditioning and Sanitary Engineers of Japan, Kagoshima, pp397-408, 2016.9 (in Japanese)

5. ASHRAE STANDARD 55-92: Environmental Condition for Human Occupancy

\section{Nomenclatures}

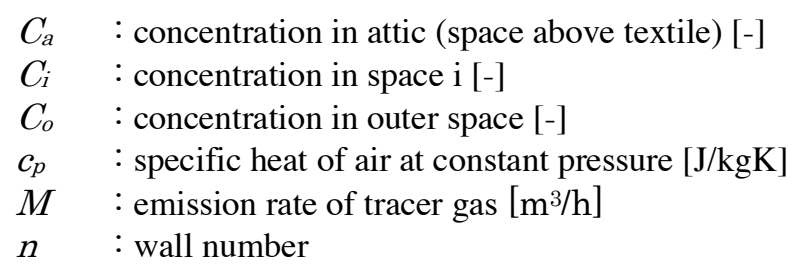

$T_{d} \quad$ : upper dome temperature of radiometer [K]

$T_{m} \quad$ : textile surface temperature $[\mathrm{K}]$

$T_{W n}:$ wall surface temperature of wall $n[\mathrm{~K}]$

$q P A C:$ removed heat rate by PAC [W]

$Q_{P A C}:$ supply airflow rate from PAC $\left[\mathrm{m}^{3} / \mathrm{h}\right]$

$V_{a} \quad:$ attic air volume $\left[\mathrm{m}^{3}\right]$

$V_{i} \quad$ : room air volume below textile $\left[\mathrm{m}^{3}\right]$

$\Delta R \quad$ : net radiation heat flow between dome of radiometer and inside wall $\&$ textile $\left[\mathrm{W} / \mathrm{m}^{2}\right]$

$\Delta R_{m}$ : net radiation heat flow between dome of radiometer and textile $\left[\mathrm{W} / \mathrm{m}^{2}\right]$

$\Delta t \quad:$ measurement/calculation time step [h]

$\mathcal{E} \quad:$ emisivity of wall and textile [-]

$\theta_{e x}:$ return air temperature of PAC $\left[{ }^{\circ} \mathrm{C}\right]$

$\theta_{s u}:$ supply air temperature of PAC $\left[{ }^{\circ} \mathrm{C}\right]$

$\rho \quad:$ air density $\left[\mathrm{kg} / \mathrm{m}^{3}\right]$

$\sigma_{b} \quad$ : Stefan-Boltzmann constant $\left(=5.67 \times 10^{-8}\right.$ $\left.\mathrm{W} / \mathrm{m}^{2} \mathrm{~K}^{4}\right)$

$\varphi_{m} \quad:$ shape factor between minute surface on the dome of radiometer and textile [-]

$\varphi_{n} \quad:$ shape factor between minute surface on the dome of radiometer and wall $n$ [-] 